\title{
Catalytic activity, water formation, and sintering: Methane activation over Co- and Fe-doped MgO nanocrystals
}

Cite as: J. Chem. Phys. 152, 074713 (2020); https://doi.org/10.1063/1.5138894

Submitted: 17 November 2019 . Accepted: 24 January 2020 . Published Online: 20 February 2020

Matthias Niedermaier, Thomas Schwab (D), Pierre Kube (D), Gregor A. Zickler (D), Annette Trunschke (D), and Oliver Diwald (D)

\section{COLLECTIONS}

Paper published as part of the special topic on Oxide Chemistry and Catalysis

Note: This paper is part of the JCP Special Topic on Oxide Chemistry and Catalysis.

\section{ARTICLES YOU MAY BE INTERESTED IN}

Reversible oxidation and reduction of gold-supported iron oxide islands at room temperature

The Journal of Chemical Physics 152, 074710 (2020); https://doi.org/10.1063/1.5136279

Probing surface defects of ZnO using formaldehyde

The Journal of Chemical Physics 152, 074714 (2020); https://doi.org/10.1063/1.5138372

Molecular chemisorption of $\mathrm{N}_{2}$ on $\mathrm{IrO}_{2}(110)$

The Journal of Chemical Physics 152, 074712 (2020); https://doi.org/10.1063/1.5142210 Find out more today
Lock-in Amplifiers

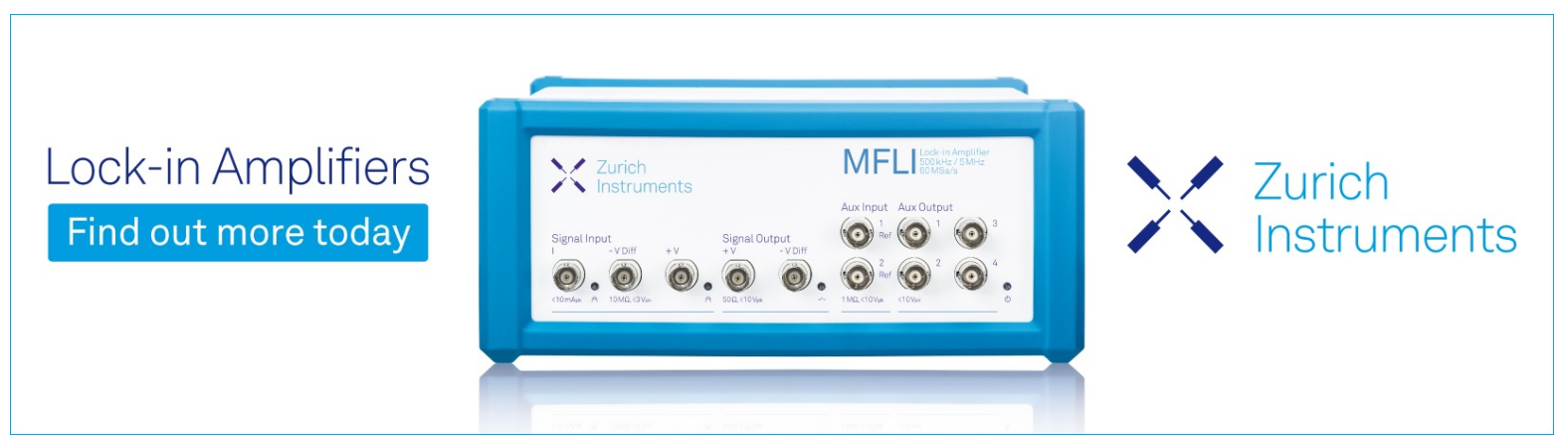

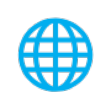




\title{
Catalytic activity, water formation, and sintering: Methane activation over Co- and Fe-doped MgO nanocrystals
}

\author{
Cite as: J. Chem. Phys. 152, 074713 (2020); doi: 10.1063/1.5138894 \\ Submitted: 17 November 2019 • Accepted: 24 January 2020 • \\ Published Online: 20 February 2020
}

\begin{abstract}
Matthias Niedermaier,' Thomas Schwab,' (D) Pierre Kube, ${ }^{2}$ (D) Gregor A. Zickler,' (D) Annette Trunschke, and Oliver Diwald ${ }^{7, b)}(\mathbb{D}$

\section{AFFILIATIONS}

${ }^{1}$ Department of Chemistry and Physics of Materials, Paris-Lodron University Salzburg, Jakob-Haringer-Strasse 2a, A-5020 Salzburg, Austria

${ }^{2}$ Department of Inorganic Chemistry, Fritz Haber Institute of the Max Planck Society, Faradayweg 4-6, D-14195 Berlin, Germany
\end{abstract}

\author{
Note: This paper is part of the JCP Special Topic on Oxide Chemistry and Catalysis. \\ a) E-mail: trunschke@fhi-berlin.mpg.de \\ ${ }^{b)}$ Author to whom correspondence should be addressed: oliver.diwald@sbg.ac.at
}

\begin{abstract}
Microstructure, structure, and compositional homogeneity of metal oxide nanoparticles can change dramatically during catalysis. Considering the different stabilities of cobalt and iron ions in the MgO host lattice [M. Niedermaier et al., J. Phys. Chem. C 123, 25991 (2019)], we employed MgO nanocube powders with or without transition metal admixtures for the oxidative coupling of methane (OCM) reaction to analyze characteristic differences in catalytic activity and sintering behavior. Undoped MgO nanocrystals exhibit the highest $\mathrm{C}_{2}$ selectivity and retain the nanocrystallinity of the starting material after $24 \mathrm{~h}$ time on stream. For the Co-Mg-O nanoparticle powder, which exhibits the highest activity and $\mathrm{CO}_{\mathrm{x}}$ selectivity and where OCM-induced coarsening is strongest, we found that the Co ${ }^{2+}$ ions remain homogeneously distributed over the $\mathrm{MgO}$ lattice. Trivalent Fe ions migrate to the surface of Fe- $\mathrm{Mg}-\mathrm{O}$ nanoparticles where they form a magnesioferrite phase $\left(\mathrm{MgFe}_{2} \mathrm{O}_{4}\right)$ with a characteristic impact on catalytic performance: $\mathrm{Fe}-\mathrm{Mg}-\mathrm{O}$ is initially less selective than $\mathrm{MgO}$ despite its lower activity. An increase in $\mathrm{C}_{2}$ selectivity and a decrease in the $\mathrm{CO}_{2} / \mathrm{CO}$ ratio with time on stream are attributed to the increasing fraction of coarsened particles that become depleted in redox active Fe. Surface water is a by-product of the OCM reaction, favors mass transport across the particle surfaces, and serves as a sintering aid during catalysis. The characteristic changes in size and morphology of $\mathrm{MgO}$, Co-doped, and Fe-doped $\mathrm{MgO}$ particles can be consistently explained by activity and $\mathrm{C}_{2}$ selectivity trends. The original morphology of the nanocubes as a starting material for the OCM reaction does not impact the catalytic activity.
\end{abstract}

\section{INTRODUCTION}

Nanoparticle powders are complex systems of matter. During operation as a catalyst, they are typically subject to structural (crystal phase, size, and morphology of the particle) and microstructural changes (aggregation, particle coalescence, and coarsening). This is particularly true for metal oxide particles in heterogeneous catalysis. Examples are catalyst coarsening and the associated reduction in the number of active surface sites. ${ }^{1-4}$ Moreover, particle reorganization and associated morphology changes can give rise to new surface features with altered activities and selectivities. ${ }^{5,6}$ Related transformation processes are additionally affected by by-products and products that form in the course of catalytic reactions.

A prominent and ubiquitous component with a substantial impact on oxide nanoparticle stability is water. ${ }^{8,9}$ For this reason, the formation and readsorption of water during catalysis ${ }^{10-14}$ has remained a key research topic in a variety of research fields that 
involve surface science, heterogeneous catalysis, and electrocatalysis in water containing liquids. ${ }^{8,15,16}$

The challenges associated with a reproducible physicochemical description of metal oxide nanoparticle systems strongly depend on the presence of water in the surrounding continuous phase. ${ }^{8,9,14} \mathrm{H}_{2} \mathrm{O}$ related and annealing induced particle transformation effects, such as coarsening and coalescence, have been observed for $\mathrm{MgO}$ nanoparticles for residual water concentrations as low as $\mathrm{p}\left(\mathrm{H}_{2} \mathrm{O}\right)=10^{-3}$ mbar. $^{14}$ A relative decrease in the thermal stability of the individual particles must also have a severe impact on the catalytic performance of oxide catalysts. This is especially relevant for reactions such as the oxidative coupling of methane (OCM) in the course of which $\mathrm{H}_{2} \mathrm{O}$ forms as a by-product. Here, water is detrimental not only as it promotes catalyst coarsening but also as catalyst deactivation may result from the hydroxylation of the particle surfaces. ${ }^{7}$ As a consequence, high temperatures are necessary process parameters to eliminate surface water from the catalyst surface during the catalytic reaction. ${ }^{5,}$

Another major issue related to the OCM reaction is the generally low selectivity of the catalysts. ${ }^{18}$ Therefore, much research has focused on the identification of appropriate catalysts that lead to higher $\mathrm{C}_{2}$ yields. ${ }^{19}$ For example, doping of metal oxides has been identified as a valuable strategy ${ }^{20,21}$ to reach this goal. ${ }^{22-25}$ Moreover, irreducible metal oxides containing admixed transition metal ions as dopants are prominent systems for oxidation catalysis.

However, with regard to structure-property relationships of metal oxide nanostructures, dopant admixture corresponds to another step in complexity increase. Isovalent impurities that are energetically stabilized in the host lattice of alkaline earth oxides as substitutional defects do not segregate during materials' operation at elevated temperatures and are generally simple to describe. This work is based on an earlier study ${ }^{1}$ that addressed the fundamental questions of how and to what extent isovalent or aliovalent ions of $\mathrm{Fe}$ and $\mathrm{Co}$ as next neighbors in the periodic table affect the crystallographic phase, size, and morphology of the $\mathrm{MgO}$ nanoparticles. We identified a defect compensation mechanism where the energetics of impurity-vacancy complexes determine the dopant's oxidation state and its segregation behavior.

Solid solutions of $\mathrm{Co}-\mathrm{Mg}-\mathrm{O}$ particles, where substitutional and divalent $\mathrm{Co}_{\mathrm{Mg}}$ sites are homogeneously distributed over the $\mathrm{MgO}$ host lattice, serve as an instructive example in this context. ${ }^{1,27}$ The situation becomes more complex for aliovalent ions that give rise to cation vacancies as intrinsic and charge compensating defects. ${ }^{2}$ Substitutional $\mathrm{Fe}^{3+}$ cations in the MgO lattice, for example, can associate with $\mathrm{Mg}$ vacancies. These impurity-vacancy complexes were found to segregate in the course of annealing into the particle surface, where they form nuclei of a newly formed magnesioferrite phase. ${ }^{1,16}$

Here, we investigate doped $\mathrm{MgO}$ nanocubes with transition metal ion concentrations up to 4 at. $\%\left(\mathrm{Co}-\mathrm{Mg}-\mathrm{O}: \mathrm{c}_{\mathrm{Co}}=2.0\right.$ and 3.5 at. $\%$ and $\mathrm{Fe}-\mathrm{Mg}-\mathrm{O}: \mathrm{c}_{\mathrm{Fe}}=1.5$ and 3.5 at. \%) and search for dopant related catalytic activity changes, on the one hand, and associated OCM reaction induced transformation behavior of the pure and doped nanoparticles, on the other hand. Special interest lies on the impact of the cobalt and iron ions in the host $\mathrm{MgO}$ lattice on the catalytic properties over time on stream (TOS), since related differences can be linked to the coarsening and sintering behavior of the catalyst particles.

The structure of this study is as follows: first, we compare structure, morphology (XRD, TEM), and the compositional distribution of the elements energy dispersive X-ray spectroscopy (EDX) spectroscopy mapping of the catalyst materials before and after their operation in the OCM reaction. Coarsening and morphology changes of $\mathrm{MgO}, \mathrm{Co}-\mathrm{Mg}-\mathrm{O}$, and $\mathrm{Fe}-\mathrm{Mg}-\mathrm{O}$ particles together with trends in impurity exsolution will be related to their catalytic performance in the OCM reaction, as described in the second part of this study.

\section{EXPERIMENTAL}

\section{Particle synthesis}

$\mathrm{Fe}-\mathrm{Mg}-\mathrm{O}$ and $\mathrm{Co}-\mathrm{Mg}-\mathrm{O}$ nanoparticles were produced via a combination of metalorganic chemical vapor synthesis (MOCVS) and a $\mathrm{MgO}$ combustion process inside a hot wall reactor system. The preparation of pure $\mathrm{MgO}$ nanoparticles is based on the controlled combustion of metal vapor with oxygen under reduced pressure. Details are given elsewhere. ${ }^{28,29}$ The metalorganic chemical vapor synthesis (MOCVS) process was adapted to obtain good control over the concentration and distribution of iron and cobalt in $\mathrm{Fe}-\mathrm{Mg}-\mathrm{O}$ and $\mathrm{Co}-\mathrm{Mg}-\mathrm{O}$ nanocomposite samples. The two-hot-zone reactor system consists of two quartz glass tubes, which are mounted concentrically inside a heating coil (first heating zone: operation temperature $\mathrm{T}_{1}$ ) followed by a ceramic tube furnace (second heating zone: operation temperature $\mathrm{T}_{2}$ ).

In the first heating zone, the inner glass tube hosts a ceramic crucible with ferrocene (98\%, Sigma Aldrich, $0.75 \mathrm{~g}$ ) or cobaltocene (Sigma Aldrich, $0.5 \mathrm{~g}$ ), which are heated to temperature $\mathrm{T}_{1}=323 \mathrm{~K}$ (ferrocene) $333 \mathrm{~K}$ (cobaltocene), respectively, in order to sublimate the metalorganic precursor and to adjust the evaporation rates. An argon gas flow (Ar 5.0, volumetric flow rate $\mathrm{Q}_{\mathrm{Ar}}=1200 \mathrm{sccm}$ ) is guided through the inner tube to transport the metalorganic vapor to the second heating zone, where the furnace provides a temperature $T_{2}=913 \mathrm{~K}$. At this position, a ceramic crucible with $\mathrm{Mg}$ metal grains (99.98\%, Alfa Aesar, $1.0 \mathrm{~g}$ ) is positioned inside the inner tube. Here, the magnesium is sublimated, and the resulting metal vapor becomes mixed with the gaseous iron or cobalt precursor. The vapor mixture is then carried by the argon gas flow to the end of the inner glass tube, where the vapor mixture reaches molecular oxygen $\left(\mathrm{O}_{2} 5.0, \mathrm{QO}_{2}=1200 \mathrm{sccm}\right)$ flowing through the outer tube. The $\mathrm{MgO}$ based nanoparticles are collected at room temperature using a stainless steel net that is kept downstream. The total pressure $\mathrm{p}=70 \pm 2 \mathrm{mbar}$, argon and oxygen flow rates, and the temperatures $T_{1}$ and $T_{2}$ of the heating zones are kept constant during the entire period of nanoparticle collection.

\section{Post synthesis annealing}

The annealing protocol corresponds to a stepwise temperature increase by $100 \mathrm{~K}$ under continuous pumping until the final temperature of $1173 \mathrm{~K}$ is reached. After each step, the temperature is dwelled under continuous pumping until the pressure falls below $10^{-5}$ mbar. At $1173 \mathrm{~K}$, molecular oxygen $\left(\mathrm{O}_{2} 5.0\right)$ is added 
and the total pressure within the system amounts to $\mathrm{p}=650 \mathrm{mbar}$. After 30 min of oxygen exposure, the powder sample is evacuated under continuous pumping for further $15 \mathrm{~min}$. This annealing cycle is repeated three times, whereas the time period of the last high vacuum step is extended to $30 \mathrm{~min}$. As a result, the sample dwells at the final temperature of $1173 \mathrm{~K}$ for a total annealing time of $150 \mathrm{~min}$.

\section{$X$-ray diffraction (XRD) and transmission electron microscopy (TEM)}

XRD measurements were performed on a Bruker AXS D8 Advance diffractometer using $\mathrm{Cu} K a$ radiation $(\lambda=154 \mathrm{pm})$. Crystalline domain sizes were determined from powder diffraction data using the Scherrer equation.

TEM data were acquired using a JEOL JEM-F200 transmission electron microscope operating at $200 \mathrm{kV}$ equipped with a cold field emission electron source and a large windowless JEOL Centurio energy dispersive X-ray emission (EDX) detector $\left(100 \mathrm{~mm}^{2}\right.$, $0.97 \mathrm{srad}$, energy resolution $<133 \mathrm{eV}$ ) for local composition analysis. EDX maps were acquired in STEM (Scanning TEM) mode with a typical beam current of $0.1 \mathrm{nA}$ and a beam diameter of $0.16 \mathrm{~nm}$ during $10-30 \mathrm{~min}$. The maps were obtained by signal integration of counts over the $\mathrm{Mg} \mathrm{Ka}$ transition line for $\mathrm{Mg}$ (integration: 1.16-1.34 keV), Fe Ka line for Fe (integration: 6.24-6.56 keV), and $\mathrm{Co} \mathrm{Ka}$ line for Co (integration: 6.76-7.09 keV). TEM images were recorded using a TVIPS F $2162 \mathrm{k}$ by $2 \mathrm{k}$ CMOS camera. TEM grids were prepared by dipping a lacey carbon grid into the powder in order to investigate structural features and the composition of material sticking to the grid.

\section{Oxidative coupling of methane (OCM)}

For the catalytic measurements, $\mathrm{MgO}, \mathrm{Co}-\mathrm{Mg}-\mathrm{O}$, and $\mathrm{Fe}-\mathrm{Mg}-\mathrm{O}$ nanoparticle powders were pressed and sieved to receive a fraction of 250-355 $\mu \mathrm{m}$ grains. $50 \mathrm{mg}$ catalyst was diluted with $50 \mathrm{mg}$ of $\mathrm{SiC}$ from the same mesh for the dissipation of reaction heat to avoid hot spots inside the catalyst bed. The resulting height of the catalytic bed was around $10 \mathrm{~mm}$.

The measurements were performed in a fixed bed reactor consisting of a quartz glass tube (outer diameter: $9 \mathrm{~mm}$, inner diameter: $7 \mathrm{~mm}$, and length: $200 \mathrm{~mm}$ ), which is tapered off downstream the catalyst bed to reduce the influence of gas phase reactions to a minimum. The reactor is heated using a tube furnace (HTM Reetz $\mathrm{GmbH}$ ) and established inside a heating cabinet, which is kept at $353 \mathrm{~K}$, to avoid the condensation of products such as $\mathrm{H}_{2} \mathrm{O}$ in the gas sampling system. The temperature was measured with the aid of a K-type thermocouple above the catalytic bed. After heating up the reactor in helium to the reaction temperature of $\mathrm{T}=1073 \mathrm{~K}$, it was kept at this temperature for $1 \mathrm{~h}$ before starting the reaction by adding the feed. The feed composition was set to $\mathrm{CH}_{4} / \mathrm{O}_{2} / \mathrm{He}=3 / 1 / 1$ with the aid of mass flow controllers (EL-FLOW, Bronkhorst) outside the heating cabinet. For each sample, the gas flow was adjusted to $180 \mathrm{ml} \mathrm{min}^{-1}$ or $20 \mathrm{ml} \mathrm{min}^{-1}$, respectively, to result in a short contact time of $\mathrm{W} / \mathrm{F}=0.0167 \mathrm{~g}_{\mathrm{Cat}} \mathrm{s} \mathrm{ml}^{-1}$ during the first $24 \mathrm{~h}$ on stream and a long contact time of $\mathrm{W} / \mathrm{F}=0.150 \mathrm{~g}_{\text {Cat }} \mathrm{s} \mathrm{ml}^{-1}$ during the second $24 \mathrm{~h}$ on stream. The pressure inside the reactor was kept at $\mathrm{p}=1$ bar during the whole experiment. With the applied parameters, the criteria of the plug flow model [Eqs. (1)-(3)] were accomplished. With $\mathrm{L}$ being the length of the catalytic bed $(\approx 10 \mathrm{~mm}), \mathrm{d}_{\mathrm{p}}$ the diameter of secondary catalyst particles $(0.250-0.355 \mathrm{~mm})$, and $d_{r}$ the diameter of the reactor $(7 \mathrm{~mm})$, the required relations are

$$
\begin{aligned}
& \frac{L}{d_{p}}>50, \\
& \frac{d_{r}}{d_{p}}>10, \\
& \frac{L}{d_{p}}>5 .
\end{aligned}
$$

Gas analysis was carried out in an Agilent 7890A gas chromatograph equipped with two channels. A combination of two capillary columns [GS-CarbonPLOT (length $30 \mathrm{~m}, 0.53 \mathrm{~mm}$ inner diameter, $40 \mathrm{~lm}$ film thickness) and HP-PLOT Molesieve/5A (length $30 \mathrm{~m}$, $0.53 \mathrm{~mm}$ inner diameter, $25 \mathrm{~lm}$ film thickness)] in connection with a thermal conductivity detector (TCD) was used to analyze the permanent gases $\mathrm{CO}_{2}, \mathrm{O}_{2}, \mathrm{He}$, and $\mathrm{CO}$. A combination of two capillary columns [HP-FFAP (length $30 \mathrm{~m}, 0.53 \mathrm{~mm}$ inner diameter, $1 \mathrm{~lm}$ film thickness) and HP-PLOT Q (length $30 \mathrm{~m}, 0.53 \mathrm{~mm}$ inner diameter, $40 \mathrm{~lm}$ film thickness)] connected to a flame ionization detector (FID) was applied to analyze alkanes and olefins $\left(\mathrm{CH}_{4}, \mathrm{C}_{2} \mathrm{H}_{6}, \mathrm{C}_{2} \mathrm{H}_{4}, \mathrm{C}_{3} \mathrm{H}_{8}\right.$, and $\mathrm{C}_{3} \mathrm{H}_{6}$ ).

The product composition was used to determine the rate of reaction, conversion, yield, and selectivity for different reactants or products. The following equation is used to calculate the reaction rate with regard to substance $i$, where $c_{i}$ is the concentration of reactants/products, $W$ the weight of the catalyst $(\mathrm{g}), F^{O}$ the flow of the reactants $(\mathrm{ml} / \mathrm{s}), v_{i}$ the stoichiometric coefficient, and $r_{i}$ the reaction rate of consumption/formation:

$$
\frac{d c_{i}}{d\left(\frac{W}{F^{o}}\right)}=-v_{i} r_{i} .
$$

The conversion of $\mathrm{O}_{2}\left(\mathrm{X}_{\mathrm{O}_{2}}\right)$ was determined by the following expression by using helium as an internal standard to exclude volume effects on gas analysis due to the high reaction temperature, where $c_{\mathrm{O}_{2} \text { in }}$ and $c_{\mathrm{He}}$ in are the $\mathrm{O}_{2}$ or $\mathrm{He}$ concentrations at the reactor inlet, respectively, whereas $c_{\mathrm{O}_{2} \text { out }}$ and $c_{\mathrm{He} \text { out }}$ are corresponding concentrations at the reactor outlet:

$$
X_{\mathrm{O}_{2}}=\frac{\frac{c_{\mathrm{O}_{2} \text { in }}}{c_{\mathrm{He} \text { in }}}-\frac{c_{\mathrm{O}_{2} \text { out }}}{c_{\mathrm{He} \text { out }}}}{\frac{c_{\mathrm{O}_{2} \text { in }}}{c_{\mathrm{He} \text { in }}}} .
$$

The conversion of $\mathrm{CH}_{4}\left(\mathrm{X}_{\mathrm{CH}_{4}}\right)$ was determined with the following equation based on the total amount of carbon atoms in the product and the unconverted $\mathrm{CH}_{4}$, with $n_{\text {C-atoms, } i}$ being the number of carbon atoms in product $i$ :

$$
X_{\mathrm{CH}_{4}}=\frac{\sum\left(\frac{n_{\mathrm{C} \text {-atoms }, i}}{n_{\mathrm{C} \text {-atoms }, \mathrm{CH}_{4}}} c_{\text {i out }}\right)-c_{\mathrm{CH}_{4} \text { out }}}{\sum\left(\frac{n_{\mathrm{C} \text {-atoms }, i}}{n_{\mathrm{C} \text {-atoms }, \mathrm{CH}_{4}}} c_{\text {i out }}\right)} .
$$

The number of carbon atoms in the product $i$ was also used to determine $S_{i}$ the selectivity for species $i$ via the following equation:

$$
S_{i}=\frac{\frac{n_{\mathrm{C}-\text { atoms }, i}}{n_{\mathrm{C} \text {-atoms }, \mathrm{CH}_{4}}} c_{\text {out }}}{\sum\left(\frac{n_{\mathrm{C} \text { atoms }, i}}{n_{\mathrm{C} \text {-atoms }, \mathrm{CH}}} c_{\text {i out }}\right)} .
$$




\section{RESULTS AND DISCUSSION}

Prior to catalysis, the metal oxide powders were annealed to $1173 \mathrm{~K}$ in alternate cycles of evacuation to pressures down to the high vacuum regime and exposed to $\mathrm{O}_{2}$ atmosphere. Figure 1 shows the characteristic transmission electron micrographs of the nanoparticle catalysts [(a)-(e)] and associated particle size distributions.

The annealed powders are made up of agglomerates containing nanoparticles with defined morphologies and narrow particle size distributions. $\mathrm{MgO}$ and $\mathrm{Co}-\mathrm{Mg}-\mathrm{O}$ nanoparticles, in particular, show sharp edges and corners underlining their cubic particle habit, which is characteristic for dehydroxylated $\mathrm{MgO}$ nanoparticles prepared using combustion techniques. ${ }^{14,30-32}$ Undoped $\mathrm{MgO}$ nanoparticles are smaller than $10 \mathrm{~nm}$ and have a mean particle size of around $5 \mathrm{~nm}$. The $\mathrm{Co}-\mathrm{Mg}-\mathrm{O}$ particle size distributions are shifted to slightly higher values as compared to $\mathrm{MgO}$. Apparently, Co doping to $\mathrm{MgO}$ shows no major effect on the structural stability of the host particles under the annealing conditions applied. Conversely, the morphology of the $\mathrm{Fe}-\mathrm{Mg}-\mathrm{O}$ nanoparticles after annealing is less defined and no cubic particle shape can be found by TEM. The particle size distribution related to the $\mathrm{Fe}-\mathrm{Mg}-\mathrm{O}$ particle powders with an integral Fe concentration of 3.5 at. \% is shifted to higher values. Particles adopt sizes up to $20 \mathrm{~nm}$, and the mean particle size of $11 \mathrm{~nm}$ exceeds that of $\mathrm{MgO}, \mathrm{Co}-\mathrm{Mg}-\mathrm{O}$, or $\mathrm{Fe}-\mathrm{Mg}-\mathrm{O}$ particles of lower Fe concentrations. Since the size and morphology of the as-synthesized $\mathrm{MgO}, \mathrm{Co}-\mathrm{Mg}-\mathrm{O}$, and $\mathrm{Fe}-\mathrm{Mg}-\mathrm{O}$ particles are comparable, one can conclude a reduced thermal stability for the annealed $\mathrm{Fe}-\mathrm{Mg}-\mathrm{O}$ nanoparticles in comparison to the other samples.

The different thermal stabilities are also reflected in the width variations of the diffraction features of the $\mathrm{X}$-ray powder diffraction patterns [Fig. 2(a)] and, therefore, in the crystallite domain sizes as determined using the Scherrer equation [Fig. 2(b)]. The determined values of the crystallite domain sizes are consistent with the TEM data derived mean particle size. All types of catalysts remain phase pure and keep their MgO-specific rock salt crystal structure after annealing to $1173 \mathrm{~K}$ in water free environments prior to catalysis. Moreover, there is no evidence for dopant induced lattice strain as one would conclude from the characteristic shift of the diffraction lines. Information about the specific surface areas ranging between $500 \mathrm{~m}^{2} \mathrm{~g}^{-1}$ and $80 \mathrm{~m}^{2} \mathrm{~g}^{-1}$ (for the as-synthesized and vacuum annealed $\mathrm{Fe}-\mathrm{Mg}-\mathrm{O}$ nanoparticle powders, respectively) as well as domain sizes is provided in the supplementary material (Tables S1 and S2).

A key question of this study relates to the stability of the structure and compositional homogeneity of the $\mathrm{MgO}$ based catalysts and its dependence on the atmospheric composition of the surrounding gas during catalysis. For this purpose, we investigated the undoped $\mathrm{MgO}$ catalyst particles after their operation for $48 \mathrm{~h}$ in the OCM reaction with transmission electron microscopy (Fig. 3).

Compared to the starting material (Fig. 1), the $\mathrm{MgO}$ catalyst particles are strongly coarsened and the particle morphology changed significantly. Moreover, we found the coexistence

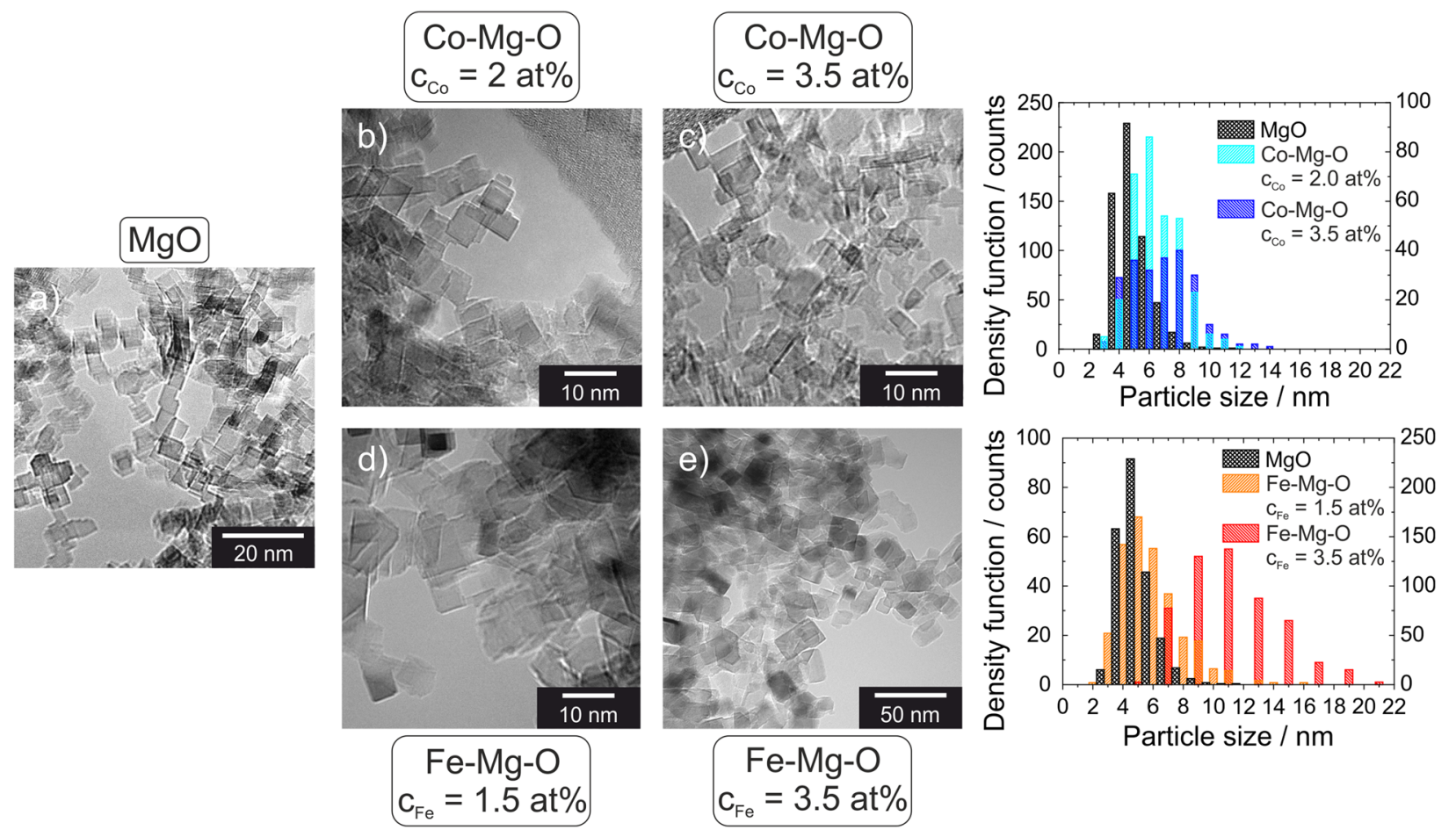

FIG. 1. TEM images (a) MgO, [(b) and (c)] Co-Mg-O, and [(d) and (e)] Fe-Mg-O nanoparticle powders as-synthesized by chemical vapor synthesis (CVS) and after annealing to $1173 \mathrm{~K}$ prior to their testing as catalysts in the OCM reaction. Particle size distributions are plotted in the right panel. 
a) X-ray diffraction pattern

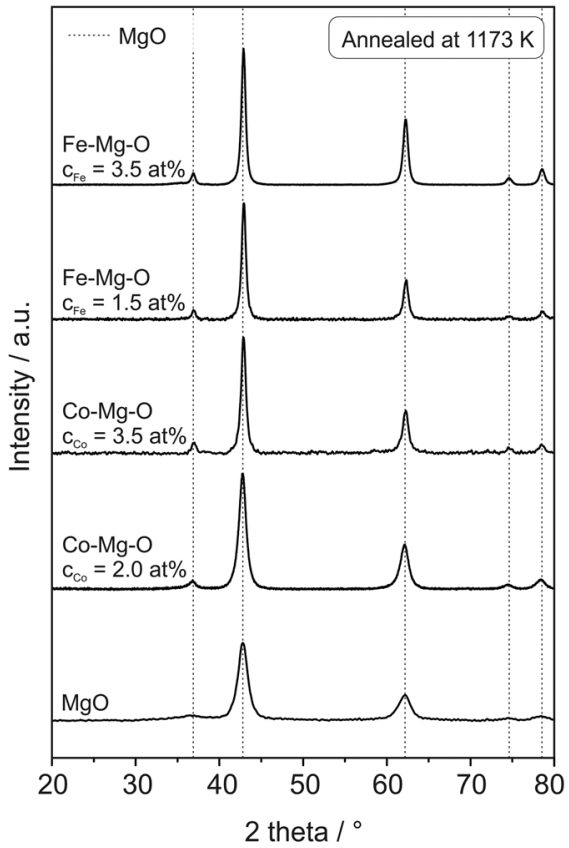

b) Crystallite domain size

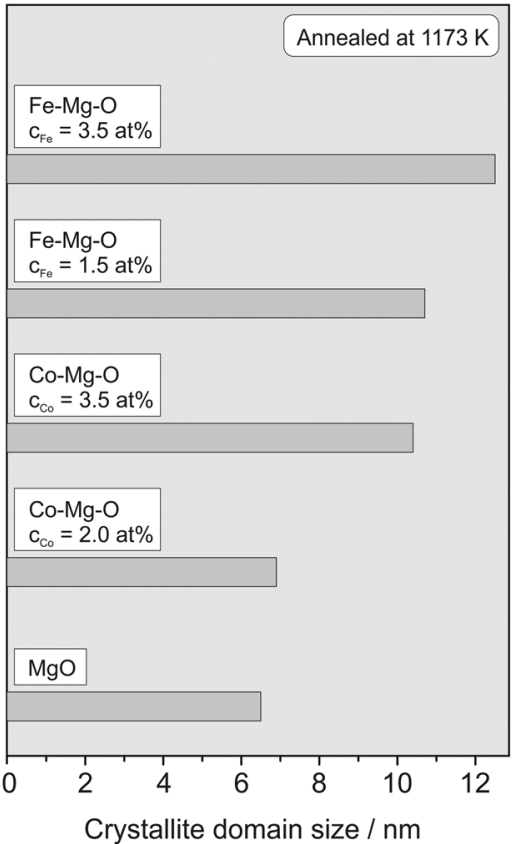

FIG. 2. (a) XRD patterns and (b) crystallite domain sizes (as determined using the Scherrer equation) of $\mathrm{MgO}$, $\mathrm{Co}-\mathrm{Mg}-\mathrm{O}\left(\mathrm{C}_{\mathrm{Co}_{0}}=2.0\right.$ and 3.5 at. \%), and $\mathrm{Fe}-\mathrm{Mg}-\mathrm{O}\left(\mathrm{C}_{\mathrm{Fe}}=1.5\right.$ and 3.5 at. \%) nanoparticle samples after annealing to $1173 \mathrm{~K}$. of a coarse grained and a fine fraction within individual particle agglomerates [Fig. 3(a), left]. Particles of the fine fraction remain smaller than $20 \mathrm{~nm}$, whereas the coarse fraction consists of particles with sizes up to a few hundreds of nanometer. As undoped $\mathrm{MgO}$
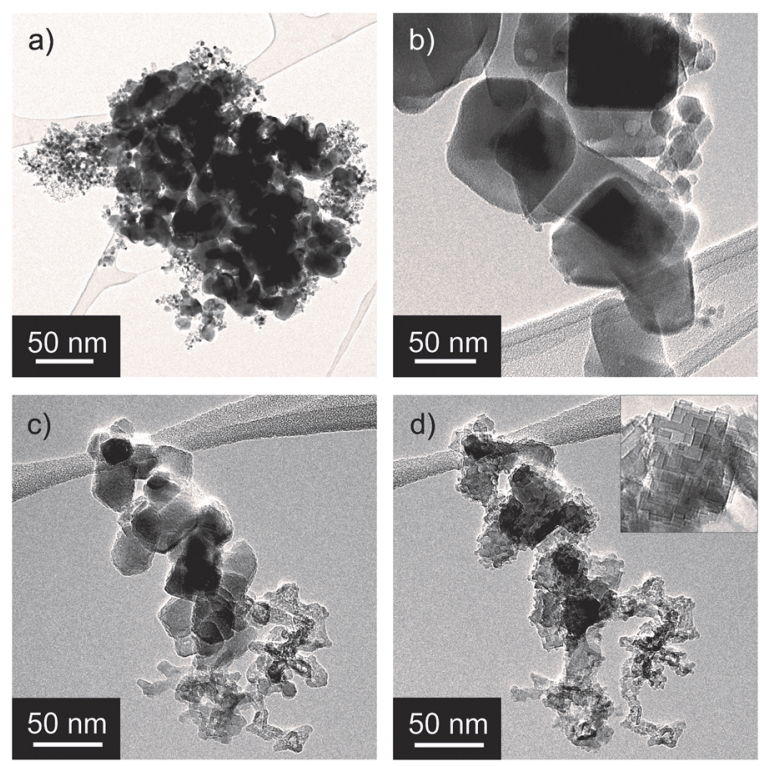

FIG. 3. Transmission electron micrographs of $\mathrm{MgO}$ nanoparticle catalysts after application in the oxidative coupling of methane reaction (TOS: $48 \mathrm{~h}, \mathrm{~T}=1073 \mathrm{~K}$, and $\mathrm{CH}_{4} / \mathrm{O}_{2} / \mathrm{He}=3: 1: 1$ ). An electron beam induced transformation effect of the coarsened aggregate can be concluded by comparison of (c) and (d). The origin of this effect is attributed to the conversion of amorphous surface hydroxides into facetted $\mathrm{MgO}$ cubelets with dehydroxylated surfaces [inset in (d)]. particles exhibit an outstandingly high stability during annealing in dry gas atmospheres, the strong coarsening is attributed to water evolution during catalysis. As a by-product of the OCM reaction, water results in hydroxylation of the metal oxide particles and even in the formation of $\mathrm{Mg}(\mathrm{OH})_{2}$ surface structures ${ }^{33}$ exhibiting decreased thermal stability. ${ }^{14}$ Water formation is also associated with the loss of the cubic particle morphology being a characteristic for the anhydrous starting material (Fig. 1). During the OCM reaction, surface elements that would be consistent with (110) or (111) faces evolve. Related features are attributed to multiple step edges, which in the presence of surface water become thermodynamically more stable. ${ }^{14}$ Moreover, we also expect the presence of amorphous surface hydroxides, which become unstable under the conditions of the TEM measurements. As a result of extended specimen exposure to the electron beam, the region surrounded by roundish surfaces was found to transform into larger steps and terraces $(c \rightarrow d)$. The beam energy resulting in a local temperature rise within the sample ${ }^{34,35}$ in combination with the high vacuum conditions within the TEM chamber ( $\mathrm{p}<10^{-7}$ mbar) favors dehydration and dehydroxylation of the particle surfaces and promotes the reformation of cube-based surface structures that terminate with $\mathrm{MgO}(100)$ faces.

TEM bright-field images and EDX spectroscopy maps of the mixed oxide catalyst $\mathrm{Fe}-\mathrm{Mg}-\mathrm{O}$ and $\mathrm{Co}-\mathrm{Mg}-\mathrm{O}$ nanoparticles after $48 \mathrm{~h}$ on stream of the OCM reaction are shown in Fig. 4.

Co impurities in Co-Mg-O catalysts remain homogeneously dispersed over the particle aggregates [Fig. 4(c)] and on the level of individual particles [Figs. 4(b) and 4(d)]. Fe admixtures in $\mathrm{Fe}-$ $\mathrm{Mg}-\mathrm{O}$, on the other hand, form Fe-rich metal oxide clusters that segregate to the surface ${ }^{1,16}$ [green arrows, Figs. $4(\mathrm{~g})$ and $4(\mathrm{~h})$ ].

The difference in the exsolution behavior of the $\mathrm{Co}$ and $\mathrm{Fe}$ cations is attributed to the different valence states the incorporated 


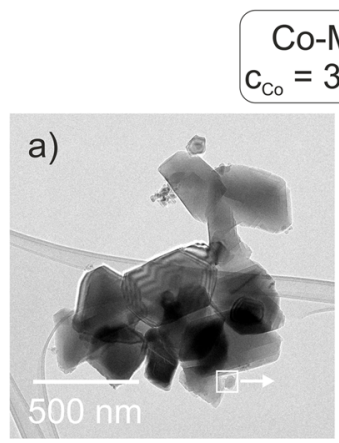

Co-Mg-O

$\mathrm{Co}_{\mathrm{Co}}=3.5$ at $\%$
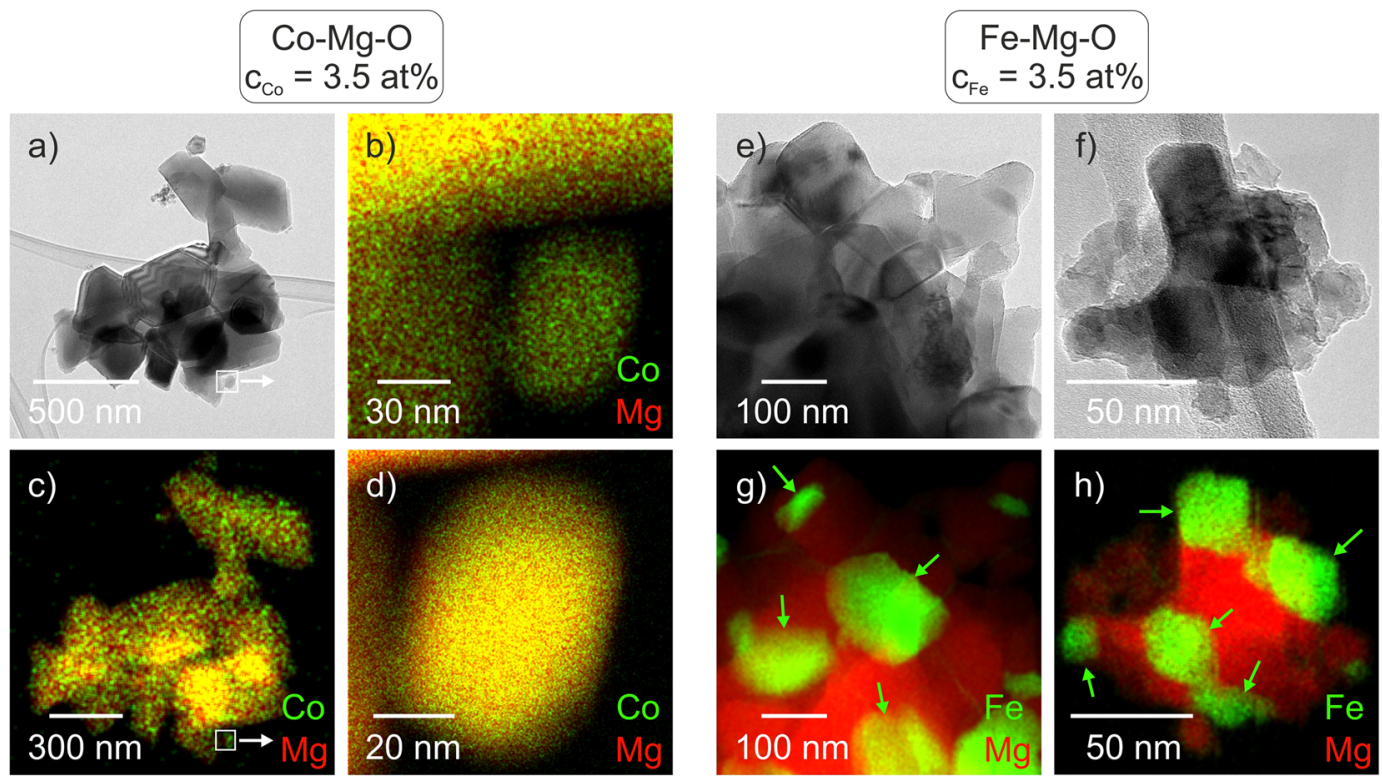

FIG. 4. TEM images and corresponding EDX spectroscopy maps of Co-Mg-O (left) and Fe-Mg-O (right) catalysts after application in the oxidative coupling of methane (TOS: $48 \mathrm{~h}, \mathrm{~T}=1073 \mathrm{~K}$, and $\mathrm{CH}_{4} / \mathrm{O}_{2} / \mathrm{He}=3: 1: 1$ ). [EDX spectroscopy: green-transition metals ( $\mathrm{Fe} / \mathrm{Co}$ ) and red-Mg].

transition metal ions adopt in the $\mathrm{MgO}$ lattice. ${ }^{1}$ By means of XAS and XPS measurements, we observed for $\mathrm{Co}-\mathrm{Mg}-\mathrm{O}$ nanoparticles that divalent Co ions prevail and remain as stable substitutional cations in the host lattice. No Co segregation or phase separation was observed for these samples. For $\mathrm{Fe}-\mathrm{Mg}-\mathrm{O}$ nanoparticles, in contrast, we found that upon extended annealing to $1173 \mathrm{~K}$ trivalent $\mathrm{Fe}$ ions migrate toward the particle surface, where they form a new Fe-rich magnesioferrite $\left(\mathrm{MgFe}_{2} \mathrm{O}_{4}\right)$ phase. ${ }^{1,16}$

It should be noted that $\mathrm{Fe}$ exsolution does also give rise to particles that become depleted in Fe with an impact on the catalytic properties which must change with time on stream. The high stability of Co ions, in contrast, is expected to keep the catalytic properties during time on stream at a constant level.

The transmission electron micrographs of the transition metal doped catalysts [Figs. 4(a), 4(e), and 4(f)] reveal strong particle coarsening effects. This effect does also apply to undoped $\mathrm{MgO}$, and the extent of coarsening is, however, significantly higher for the doped metal oxide systems. As an additional observation, we did not find any fine fraction in transition metal doped catalysts after the OCM reaction, and the particle size distributions are generally shifted to higher values as compared to undoped $\mathrm{MgO}$ (Fig. 5). Particle sizes as large as $350 \mathrm{~nm}$ were found in the samples that were previously used as $\mathrm{Co}-\mathrm{Mg}-\mathrm{O}$ catalyst. The different extent of coarsening is attributed to

(i) transition metal ion admixture: especially aliovalent impurity ions decrease the thermal stability of the host, as charge compensating vacancies enhance ion diffusion in the solid ${ }^{1}$ and

(ii) changes in the chemical composition of the surrounding gas atmosphere: depending on the activity and selectivity of the catalyst in the OCM reaction, the concentration of water and other by-products may be very different. Higher $\mathrm{CH}_{4}$ conversion values or $\mathrm{CO}_{\mathrm{x}}$ selectivities are associated with higher $\mathrm{H}_{2} \mathrm{O}$ production rates and, therefore, with a higher water vapor pressure inside the catalytic reactor. This decreases the thermal stability of MgO based catalysts ${ }^{14}$ and, hence, explains the variations in the level of coarsening observed.

To compare the catalytic properties of the different catalysts, we determined kinetic data at short contact times to avoid full oxygen conversion. This results in fairly low reaction rates but allows

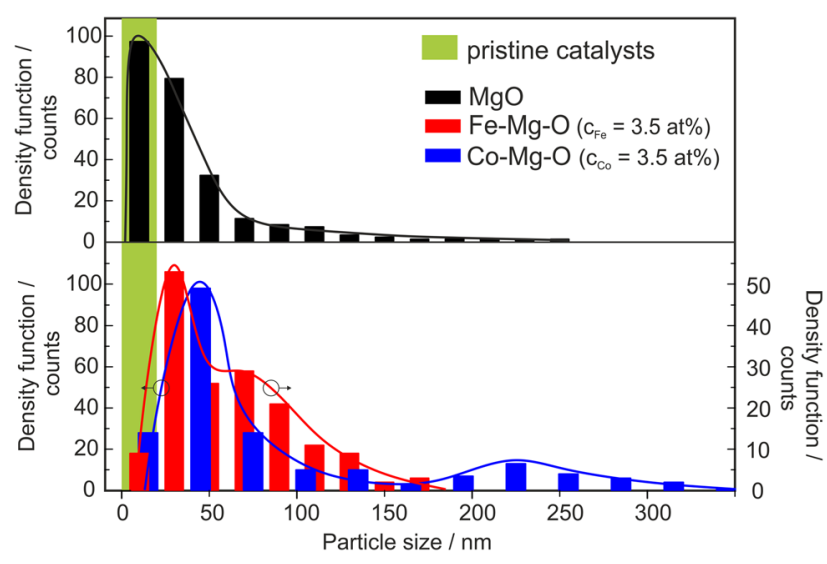

FIG. 5. Particle size distribution plots of $\mathrm{MgO}, \mathrm{Fe}-\mathrm{Mg}-\mathrm{O}$ ( $\mathrm{C}_{\mathrm{Fe}}=3.5$ at. \%), and $\mathrm{Co}-\mathrm{Mg}-\mathrm{O}\left(\mathrm{c}_{\mathrm{C}_{0}}=3.5\right.$ at. \%) catalyst particles after their application in the oxidative coupling of methane reaction (TOS: $48 \mathrm{~h}, \mathrm{~T}=1073 \mathrm{~K}$, and $\mathrm{CH}_{4} / \mathrm{O}_{2} / \mathrm{He}=3: 1: 1$ ). 
TABLE I. Consumption rates of methane, formation rates of $\mathrm{C}_{2}$, conversion and selectivity values measured for $\mathrm{MgO}, \mathrm{Fe}-\mathrm{Mg}-\mathrm{O}$, and $\mathrm{Co}-\mathrm{Mg}-\mathrm{O}$ catalysts in the $\mathrm{OCM}$ in the initial state $(\mathrm{t}=0)$ at $\mathrm{T}=1073 \mathrm{~K}$ (feed composition: $\mathrm{CH}_{4} / \mathrm{O}_{2} / \mathrm{He}=3 / 1 / 1$ and $\mathrm{W} / \mathrm{F}=0.0167 \mathrm{~g} \mathrm{~s} \mathrm{ml}^{-1}$ ).

\begin{tabular}{|c|c|c|c|c|c|c|c|}
\hline Sample & $\begin{array}{c}\mathrm{r}\left(\mathrm{CH}_{4}\right) \\
\left(\mu \mathrm{mol} \mathrm{s}{ }^{-1} \mathrm{~g}_{\mathrm{cat}}^{-1}\right)\end{array}$ & $\begin{array}{c}\mathrm{r}\left(\mathrm{C}_{2}\right) \\
\left(\mu \mathrm{mol} \mathrm{s}{ }^{-1} \mathrm{~g}_{\mathrm{cat}}{ }^{-1}\right)\end{array}$ & $\begin{array}{c}\mathrm{X}\left(\mathrm{CH}_{4}\right) \\
(\%)\end{array}$ & $\begin{array}{c}\mathrm{X}\left(\mathrm{O}_{2}\right) \\
(\%)\end{array}$ & $\begin{array}{l}\mathrm{S}\left(\mathrm{C}_{2}\right) \\
(\%)\end{array}$ & $\mathrm{CO}_{2} / \mathrm{CO}^{\mathrm{a}}$ & $\mathrm{C}_{2} \mathrm{H}_{4} / \mathrm{C}_{2} \mathrm{H}_{6}{ }^{\mathrm{a}}$ \\
\hline $\mathrm{MgO}$ & 313.3 & 44.0 & 19.5 & 51.2 & 34.9 & 0.48 & 1.46 \\
\hline $\mathrm{Fe}-\mathrm{Mg}-\mathrm{O}\left(\mathrm{c}_{\mathrm{Fe}}=1.5\right.$ at. $\left.\%\right)$ & 101.9 & 5.6 & 6.7 & 31.9 & 12.2 & 1.51 & 0.28 \\
\hline $\mathrm{Fe}-\mathrm{Mg}-\mathrm{O}\left(\mathrm{c}_{\mathrm{Fe}}=3.5\right.$ at. $\left.\%\right)$ & 104.4 & 7.5 & 6.6 & 32.4 & 17.2 & 4.03 & 0.33 \\
\hline $\mathrm{Co}-\mathrm{Mg}-\mathrm{O}\left(\mathrm{c}_{\mathrm{Co}}=2.0\right.$ at. $\left.\%\right)$ & 429.9 & 36.1 & 27.4 & 99.7 & 21.5 & 2.74 & 1.23 \\
\hline $\mathrm{Co}-\mathrm{Mg}-\mathrm{O}\left(\mathrm{c}_{\mathrm{Co}}=3.5\right.$ at. \%) & 484.8 & 17.4 & 30.4 & 99.7 & 9.5 & 2.28 & 0.61 \\
\hline
\end{tabular}

${ }^{a}$ Ratio of selectivity.

for a reliable comparison. Table I shows that Co-doping increases the activity of the $\mathrm{MgO}$ catalyst, whereas Fe-doping decreases the reaction rates. Despite the short contact times, almost full conversion of oxygen is achieved for $\mathrm{Co}-\mathrm{Mg}-\mathrm{O}$ catalysts. To some extent, the initially weak $\mathrm{CH}_{4}$ conversion observed for $\mathrm{Fe}-\mathrm{Mg}-\mathrm{O}$ catalysts is attributed to the more pronounced coarsening that the material undergoes during the annealing induced catalyst preparation prior to catalysis (Figs. 1 and 2).

As a first general observation, transition metal doping gives rise to lower $\mathrm{C}_{2}$ selectivities as compared to the undoped $\mathrm{MgO}$ catalyst, however, at higher methane conversion in the case of the $\mathrm{Co}-\mathrm{Mg}-$ $\mathrm{O}$ catalysts and lower oxygen conversion over $\mathrm{Fe}-\mathrm{Mg}-\mathrm{O}$, despite lower methane conversion for the $\mathrm{Fe}-\mathrm{Mg}-\mathrm{O}$ catalysts and higher oxygen conversion for $\mathrm{Co}-\mathrm{Mg}-\mathrm{O}$ catalysts. Apparently, the redoxactive transition metals promote $\mathrm{CH}_{4}$ oxidation to $\mathrm{CO}$ and $\mathrm{CO}_{2}$ and eventually block active sites such as step edges for $\mathrm{C}_{2}{ }^{22}$ coupling. ${ }^{6,36}$ This applies, in particular, for $\mathrm{Fe}-\mathrm{Mg}-\mathrm{O}$ catalysts where $\mathrm{Fe}$ enrichment at the surface is an intermediate stage of the observed exsolution process. A problem in the OCM reaction is the catalytic postcombustion reaction of ethylene and its detrimental effect on the $\mathrm{C}_{2}$ selectivity. The contribution of post-combustion can be concluded from the development of the $\mathrm{C}_{2} \mathrm{H}_{4} / \mathrm{C}_{2} \mathrm{H}_{6}$ ratio, which decreases with transition metal doping. This points to the fact that transition metal impurities in $\mathrm{MgO}$ enhance ethylene conversion into $\mathrm{CO}$ or $\mathrm{CO}_{2}$ and, thus, decreases the $\mathrm{C}_{2}$ selectivity.

The deactivation behavior of the different catalysts is revealed by Fig. 6 showing the $C_{2}$ hydrocarbon yield and selectivity over the time on stream. During the first few hours on stream, the $\mathrm{C}_{2}$ yield of the pure $\mathrm{MgO}$ catalyst decreases strongly. This trend is attributed to particle growth and a resulting decrease in specific surface area. This type of deactivation is comparable with deactivation effects that are reported for other $\mathrm{MgO}$ catalysts tested for the OCM reaction. ${ }^{5}$ Much slower deactivation is found for the $\mathrm{Co}-\mathrm{Mg}-\mathrm{O}$ catalyzed reactions. The $\mathrm{C}_{2}$ yield peaks after $0.5 \mathrm{~h}$ at $4.6 \%$ and $6.4 \%$ for Co concentrations of 1.5 at. \% and 3.5 at. \%, respectively, and remains fairly stable over the entire time on stream beyond that. This interesting stabilization effect in combination with the high activity (see Table I) is associated with a continuously high rate of water production, which would explain the strong coarsening effects observed in Co-Mg-O catalysts (see Fig. 5). As expected from the low activity and $\mathrm{C}_{2}$ selectivity (see Table I), the $\mathrm{C}_{2}$ yield of the $\mathrm{Fe}-\mathrm{Mg}-\mathrm{O}$ catalysts is lowest compared to pure $\mathrm{MgO}$ and $\mathrm{Co}-\mathrm{Mg}-\mathrm{O}$ [Fig. 6(a)]. For both concentrations investigated, the $\mathrm{Fe}-\mathrm{Mg}-\mathrm{O}$ catalysts show interesting trends in the $\mathrm{C}_{2}$ selectivity during the catalytic test [Fig. 6(b)]. The observed increase with time on stream is consistent with a progressing Fe segregation, where the formation a)

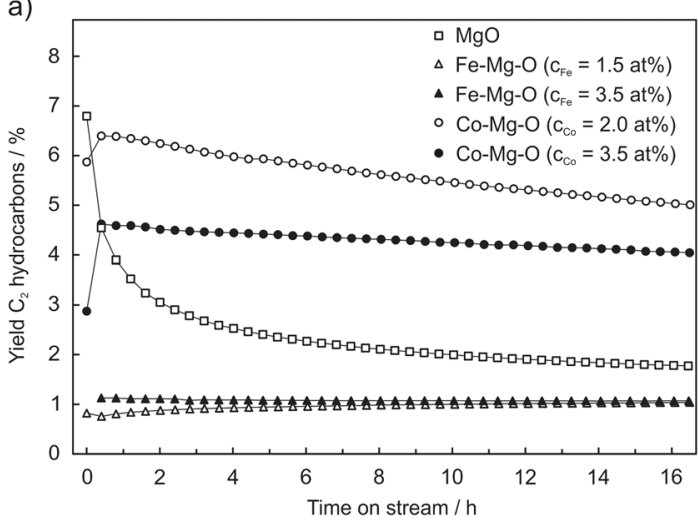

b)

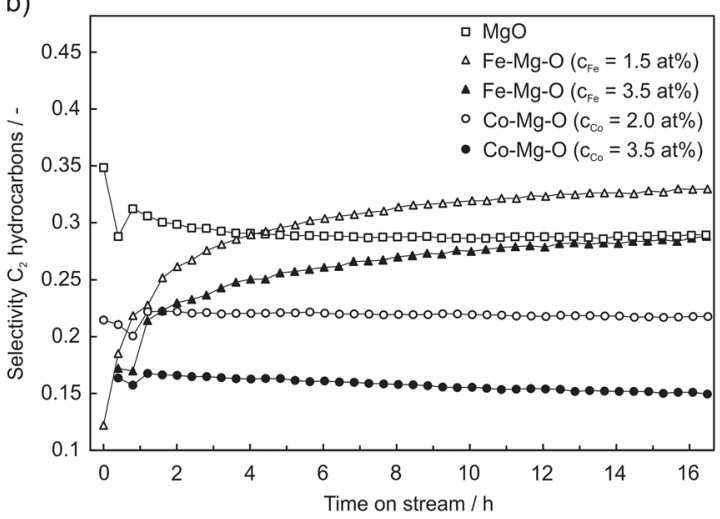

FIG. 6. $C_{2}$ yield (a) and selectivity (b) over time on stream in the OCM reaction using different MgO based nanoparticle catalysts. $T=1073 \mathrm{~K}, \mathrm{~W} / \mathrm{F}=0.0167 \mathrm{~g} \mathrm{~s} \mathrm{ml}^{-1}$, and $\mathrm{CH}_{4} / \mathrm{O}_{2} / \mathrm{Ar}=3: 1: 1$. 
of an Fe-rich $\mathrm{MgFe}_{2} \mathrm{O}_{4}$ phase ${ }^{1,16}$ (green domains in Fig. 4) leads to an increasing fraction of $\mathrm{Fe}$-poor $\mathrm{MgO}$ particles with related surfaces (red domains in Fig. 4). These exhibit a higher selectivity with respect to $\mathrm{C}_{2}$ hydrocarbon formation than Fe-rich surfaces and, hence, increase the overall $\mathrm{C}_{2}$ selectivity of the catalyst with time. For the $\mathrm{Co}-\mathrm{Mg}-\mathrm{O}$ catalysts and without any evidence for Co impurity segregation, we have not observed a related change in the $\mathrm{C}_{2}$ selectivity.

These findings are also supported by the trends in $\mathrm{CO}$ and $\mathrm{CO}_{2}$ selectivity over the time on stream (see Fig. $\mathrm{S} 1$ of the supplementary material) and by the evolution of the $\mathrm{CO}_{2} / \mathrm{CO}$ ratio during the reaction (see Fig. 7). Total oxidation is favored for higher concentrations of admixed transition metal ions, which underlines their key role in the conversion of $\mathrm{CH}_{4}$ into $\mathrm{CO}_{2}$. A decrease in total oxidation during time on stream is observed for all catalysts and is most pronounced for $\mathrm{Fe}-\mathrm{Mg}-\mathrm{O}$ catalysts. This, again, would be consistent with the progressing Fe segregation during the first few hours on stream, which leads to a decrease in the abundance of Fe-rich surfaces.

We also investigated the catalytic performance at higher contact times in the steady state of the reaction at a methane conversion of $24 \%$ (Fig. 8 and Table S3 of the supplementary material). We observe a decrease in $\mathrm{C}_{2}$ selectivity of up to $25 \%$ (Fig. 8, left) and a strong increase in $\mathrm{CO}_{2} / \mathrm{CO}$ ratio (Fig. 8, right) as a result of the admixture of the redox-active transition metal ions.

Morphology and size of pure and composite nanoparticles can undergo major changes in the course of high temperature applications such as in heterogeneous catalysis. The surrounding atmosphere plays a decisive role in coarsening, sintering, or reorganization of particle surfaces. An additional issue represents the stability of impurities in the host lattice of the binary metal oxides. Undesired dopant segregation and exsolution can occur especially for non-equilibrium nanoparticles and can influence catalytic properties during time on stream. The stability of impurities in the host lattice depends on defect energies at bulk and surface sites ${ }^{37}$ and affects processes such as defect clustering and/or impurity migration. ${ }^{1}$ Both effects contribute to the here observed selectivity changes

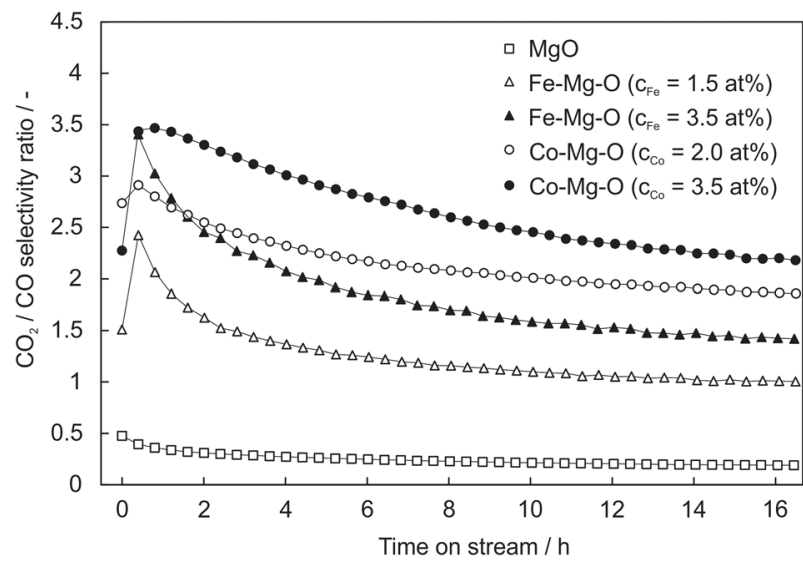

FIG. 7. $\mathrm{CO}_{2} / \mathrm{CO}$ selectivity ratio over time on stream in the OCM reaction for different $\mathrm{MgO}$ based nanoparticle catalysts. $\mathrm{T}=1073 \mathrm{~K}, \mathrm{~W} / \mathrm{F}=0.0167 \mathrm{~g} \mathrm{~s} \mathrm{ml}^{-1}$, and $\mathrm{CH}_{4} / \mathrm{O}_{2} / \mathrm{Ar}=3: 1: 1$.

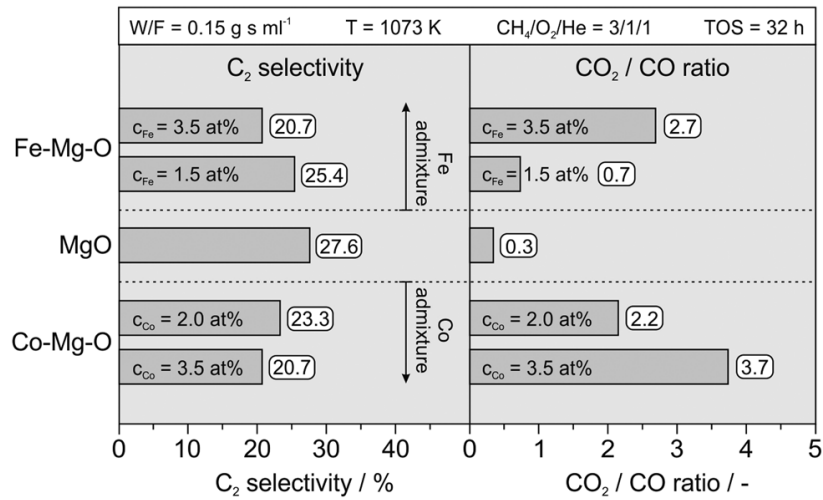

FIG. 8. $\mathrm{C}_{2}$ hydrocarbon selectivity $\mathrm{CO}_{2} / \mathrm{CO}$ selectivity ratio of $\mathrm{MgO}$, $\mathrm{Fe}-\mathrm{Mg}-\mathrm{O}$, and $\mathrm{Co}-\mathrm{Mg}-\mathrm{O}$ catalysts in the OCM reaction measured at steady state and after $32 \mathrm{~h}$ on stream $\left(\mathrm{T}=1073 \mathrm{~K}\right.$, feed composition: $\mathrm{CH}_{4} / \mathrm{O}_{2} / \mathrm{He}=3 / 1 / 1$, contact time: $0.15 \mathrm{~g} \mathrm{~s} \mathrm{ml}^{-1}$, and $\left.X\left(\mathrm{CH}_{4}\right)=24.3 \pm 1.2 \%\right)$

the $\mathrm{Fe}-\mathrm{Mg}-\mathrm{O}$ nanoparticles exhibit during the time on stream. The introduction of aliovalent impurities to the $\mathrm{MgO}$ host lattice favors the formation of intrinsic charge compensating defects, such as cation vacancies, which additionally enhance ion diffusion and coarsening.

In $\mathrm{Co}-\mathrm{Mg}-\mathrm{O}, \mathrm{Co}^{2+}$ ions inside the $\mathrm{MgO}$ host lattice exhibit high stability. Their uniform and constant dispersion over the $\mathrm{MgO}$ nanoparticles provides fairly constant selectivity values over the time on stream. For discussing the case of $\mathrm{Fe}-\mathrm{Mg}-\mathrm{O}$, one needs to consider that-even at the temperatures during catalysis $(\mathrm{T}=1073 \mathrm{~K})$ - the composite nanoparticles remain far from thermodynamic equilibrium. This explains that impurity segregation and even phase separation with $\mathrm{MgFe}_{2} \mathrm{O}_{4}$ formation can occur, having a significant impact on the catalytic properties. Theory revealed that methane activation on alkaline earth oxide catalysts occurs preferentially through a surface-mediated mechanism. ${ }^{38}$ In the transition state, one of the $\mathrm{C}-\mathrm{H}$ bonds in the adsorbed $\mathrm{CH}_{4}$ molecule is weakened by the interaction of one of the hydrogen atoms with a surface oxygen, while the methyl group interacts with either an alkaline earth or a dopant ion. ${ }^{20}$ Doping increases the rate when the bond between the hydrogen atom and the surface oxygen is enforced. Too strong bonding, on the other hand, results in catalyst deactivation. The remarkable high stability of the $\mathrm{Co}-\mathrm{Mg}-\mathrm{O}$ catalyst with time on stream suggests that the number of Co sites on the surface of the catalyst is apparently not much affected by the morphological changes occurring under reaction conditions (Fig. 5). The experimental results are in perfect accordance with scaling relations that predict exceptional high turnover frequencies for Co-doped $\mathrm{MgO}^{21}$ The agreement between experiment and theory is attributed to the high structural stability of the Co-Mg-O system in the OCM feed at $1073 \mathrm{~K}$. Respective prediction, however, fails in the case of $\mathrm{Fe}-\mathrm{Mg}-\mathrm{O}$ because under the conditions of the OCM reaction, iron is not stable in the cubic $\mathrm{MgO}$ lattice and dopant segregation including $\mathrm{MgFe}_{2} \mathrm{O}_{4}$ formation ${ }^{16}$ was not considered in the underlying calculations that imply stability of the structural system.

An important issue is the composition and catalyst activity related changes of the surrounding gas atmosphere and their impact 
on catalyst coarsening and deactivation. In the OCM reaction, $\mathrm{H}_{2} \mathrm{O}$ represents an unavoidable by-product, which enhances particle growth and sintering of the $\mathrm{MgO}$ based nanoparticle catalysts. Surface hydration and hydroxylation enables dissolution and transport of $\mathrm{OH}$-solvated $\mathrm{Mg}^{2+}$ ions promoting particle growth. ${ }^{14}$ The catalytic properties of the catalyst determine the water vapor pressure in the reactor system: a higher $\mathrm{CH}_{4}$ reaction rate and enhanced $\mathrm{CO}_{2}$ selectivity increase the concentration of $\mathrm{H}_{2} \mathrm{O}$ within the reactor system. Partial or total oxidation of $\mathrm{CH}_{4}$ to $\mathrm{CO}$ or $\mathrm{CO}_{2}$, respectively, corresponds to the full conversion of the methane hydrogen into $\mathrm{H}_{2} \mathrm{O}$, whereas $\mathrm{C}_{2} \mathrm{H}_{4}$ or $\mathrm{C}_{2} \mathrm{H}_{6}$ formation is only associated with the conversion of 50 or $25 \%$ of the hydrogen atoms in $\mathrm{CH}_{4}$ into water, respectively. If the entire amount of $\mathrm{H}_{2} \mathrm{O}$ would be in the gas-phase, a $\mathrm{CH}_{4}$ conversion value of $20 \%$ would imply a minimum partial $\mathrm{H}_{2} \mathrm{O}$ pressure of $\mathrm{p}\left(\mathrm{H}_{2} \mathrm{O}\right)=60$ mbar in the system with the here applied conditions $\left(\mathrm{CH}_{4} / \mathrm{O}_{2} / \mathrm{He}=3: 1: 1\right.$ and $\left.\mathrm{p}=1 \mathrm{bar}\right)$. Depending on the selectivity to $\mathrm{CO}_{\mathrm{x}}, \mathrm{C}_{2} \mathrm{H}_{4}$, and $\mathrm{C}_{2} \mathrm{H}_{6}$ of the given catalyst, the partial pressure can be in the range between $\mathrm{p}\left(\mathrm{H}_{2} \mathrm{O}\right)=60$ mbar and 230 mbar. At higher $\mathrm{CH}_{4}$ conversions, these values would increase even further. Knowing that for $\mathrm{MgO}$ nanoparticles, a background water vapor pressure of $\mathrm{p}\left(\mathrm{H}_{2} \mathrm{O}\right)=10^{-3} \mathrm{mbar}$ already promotes substantial coarsening of the particles, ${ }^{8,14}$ severe mass transport across the particle surfaces and interfaces as well as related particle reorganization phenomena-as shown for the here investigated catalysts-can be consistently explained. Variations in the effective water vapor pressure are reflected in the transformation behavior of the particles: the $\mathrm{Co}-\mathrm{Mg}-\mathrm{O}$ catalysts, which exhibit the highest activity and $\mathrm{CO}_{\mathrm{x}}$ selectivity, show the strongest OCM-driven coarsening effects. The pure $\mathrm{MgO}$ catalyst, on the other hand, shows the highest $\mathrm{C}_{2}$ selectivity and after catalysis still contains a fine particle fraction with particles below $20 \mathrm{~nm}$ (Figs. 3 and 5). Here, we speculate that the lower the $\mathrm{C}_{2}$ selectivity the higher the concentration of formed water and the water vapor pressure during operation of the catalyst.

\section{CONCLUSIONS}

We investigated the impact of iron or cobalt ions as dopants for $\mathrm{MgO}$ nanocrystals on the stability and segregation behavior of the particles, on the one hand, and searched for oxidative coupling of methane (OCM) reaction associated changes in catalytic activity, on the other hand. Powders of doped nanoparticles were synthesized via injection of metalorganic precursors into the magnesium combustion flame in the gas phase followed by temperature quenching of the resulting nanocrystals in argon. While $\mathrm{Co}^{2+}$ ions keep their divalent valence state and substitute $\mathrm{Mg}^{2+}$ ions in the cationic sublattice, $\mathrm{Fe}^{3+}$ ions emerge due to the energy gain released via charge compensation and impurity-vacancy complex formation and tend to accumulate in the particle surfaces as a result of impurity segregation. The very different trends in redox stability and defect formation have a significant impact on the initial activity and selectivity values and, moreover, on OCM-induced particle morphology evolution. $\mathrm{H}_{2} \mathrm{O}$ as an unavoidable by-product of the OCM reaction promotes particle growth and sintering. ${ }^{14}$ As a result, the particles undergo substantial coarsening and transform into larger grains with rounded surface features. Thus, the initial nanoparticle morphology specific to the starting material-i.e., the cubic habit of the nanocrystals-does not exert any major influence on catalytic activity and $\mathrm{C}_{2}$ selectivity. All types of particle powders undergo substantial coarsening and-in the case of the $\mathrm{Fe}-\mathrm{Mg}-\mathrm{O}$ samples-even exhibit dopant exsolution to form a Fe-rich magnesioferrite $\left(\mathrm{MgFe}_{2} \mathrm{O}_{4}\right)$ phase. The larger size and the less-regular shape of the grains as observed by TEM analysis of samples after the OCM reaction ( $24 \mathrm{~h}$ time on stream) result from the substantial depletion in $\mathrm{MgO}(100)$ faces and are related to the generation of hydroxylated step edges of variable heights as less regular surface features.

Redox-active transition metal ions that are homogeneously distributed over the $\mathrm{MgO}$ host matrix give rise to higher $\mathrm{CO}_{\mathrm{x}}$ and, in particular, higher $\mathrm{CO}_{2}$ selectivity values, and-at the same timehigher $\mathrm{H}_{2} \mathrm{O}$ production rates. This trend is strongest for $\mathrm{Co}-\mathrm{Mg}-\mathrm{O}$ nanoparticles samples where the catalyst material ultimately undergoes the most pronounced coarsening effects due to its very high activity, i.e., due to the high partial pressure of water within the catalyst bed. This, however, has no significant implication on the $\mathrm{C}_{2}$ yield. The weak response of the catalytic performance in relation to the pronounced particle coarsening effects with time on stream indicates that the catalytic properties of $\mathrm{Co}-\mathrm{Mg}-\mathrm{O}$ are dominated by the transition metal dopant and not by particle morphology and intrinsic surface defects. Apparently, as long as the dopant ions remain highly dispersed in the $\mathrm{MgO}$ matrix, the catalysts exhibit high stability in OCM.

The present study underlines that unsupported metal oxide nanoparticle systems are very dynamic systems during the catalytic reaction. This is particularly true when water forms as a by-product to act as a two-dimensional solvent that promotes mass transport and reorganization of the surface topology. ${ }^{14}$ The rationalization of underlying sintering effects represents an important prerequisite for surface science and catalysis research aiming at nanostructured catalyst design. Related particle transformation steps can produce new surface features that, ultimately, give rise to improved catalyst activity and selectivity values.

\section{SUPPLEMENTARY MATERIAL}

See the supplementary material for materials characterization data (crystallite domain sizes and specific surface areas) and additional activity and selectivity data related to the OCM reaction.

\section{ACKNOWLEDGMENTS}

The authors gratefully acknowledge support from the Austrian Science Fund FWF for Project No. P-28797. TEM measurements were carried out on a JEOL JEM F200 TEM, which was funded by Interreg Österreich-Bayern 2014-2020 (Project No. AB29)"n2m", nano-to-macro in lightweight materials.

\section{REFERENCES}

${ }^{1}$ M. Niedermaier, T. Schwab, P. Dolcet, J. Bernardi, S. Gross, M. Bockstedte, and O. Diwald, J. Phys. Chem. C 123, 25991 (2019).

${ }^{2}$ J. G. McCarty, G. Malukhin, D. M. Poojary, A. K. Datye, and Q. Xu, J. Phys. Chem. B 109, 2387 (2005).

${ }^{3}$ N. E. Tsakoumis, M. Rønning, Ø. Borg, E. Rytter, and A. Holmen, Catal. Today 154, 162 (2010)

${ }^{4}$ S. Pak and J. H. Lunsford, Appl. Catal., A 168, 131 (1998). 
${ }^{5}$ P. Schwach, W. Frandsen, M.-G. Willinger, R. Schlögl, and A. Trunschke, J. Catal. 329, 560 (2015).

${ }^{6}$ J. Hargreaves, G. Hutchings, R. W. Joyner, and C. J. Kiely, Catal. Today 13, 401 (1992).

${ }^{7}$ L. Thum, M. Rudolph, R. Schomäcker, Y. Wang, A. Tarasov, A. Trunschke, and R. Schlögl, J. Phys. Chem. C 123, 8018 (2018).

${ }^{8}$ G. R. Bourret and O. Diwald, J. Mater. Res. 34, 428 (2019).

${ }^{9}$ M. Sterrer, N. Nilius, S. Shaikhutdinov, M. Heyde, T. Schmidt, and H.-J. Freund, J. Mater. Res. 34, 360 (2019).

${ }^{10}$ Z. Gao and Y. Shi, J. Nat. Gas Chem. 19, 173 (2010).

${ }^{11}$ C. Chizallet, G. Costentin, M. Che, F. Delbecq, and P. Sautet, J. Phys. Chem. B 110, 15878 (2006).

${ }^{12}$ C. Chizallet, G. Costentin, M. Che, F. Delbecq, and P. Sautet, J. Am. Chem. Soc. 129, 6442 (2007).

${ }^{13}$ E. Knözinger, K.-H. Jacob, S. Singh, and P. Hofmann, Surf. Sci. 290, 388 (1993).

${ }^{14}$ D. Thomele, A. R. Gheisi, M. Niedermaier, M. S. Elsässer, J. Bernardi, H. Grönbeck, and O. Diwald, J. Am. Ceram. Soc. 101, 4994 (2018).

${ }^{15} \mathrm{~J}$. J. Calvin, P. F. Rosen, N. L. Ross, A. Navrotsky, and B. F. Woodfield, J. Mater. Res. 34, 416 (2019).

${ }^{16} \mathrm{M}$. Niedermaier, P. Dolcet, A. R. Gheisi, G. Tippelt, W. Lottermoser, S. Gross, J. Bernardi, and O. Diwald, J. Phys. Chem. C 121, 24292 (2017).

${ }^{17}$ T. Ito, T. Watanabe, T. Tashiro, and K. Toi, J. Chem. Soc. Faraday Trans. 185 , 2381 (1989).

${ }^{18}$ R. Horn and R. Schlögl, Catal. Lett. 145, 23 (2015).

${ }^{19}$ U. Zavyalova, M. Holena, R. Schlögl, and M. Baerns, ChemCatChem 3, 1935 (2011).

${ }^{20}$ H. Aljama, J. K. Nørskov, and F. Abild-Pedersen, J. Phys. Chem. C 121, 16440 (2017).

${ }^{21}$ H. Aljama, J. K. Nørskov, and F. Abild-Pedersen, J. Phys. Chem. C 122, 22544 (2018).
${ }^{22}$ P. Schwach, M. G. Willinger, A. Trunschke, and R. Schlogl, Angew. Chem., Int. Ed. 52, 11381 (2013).

${ }^{23}$ U. Zavyalova, G. Weinberg, W. Frandsen, F. Girgsdies, T. Risse, K. P. Dinse, R. Schloegl, and R. Horn, Chem CatChem 3, 1779 (2011).

${ }^{24}$ Z. Zhang, X. E. Verykios, and M. Baerns, Catal, Rev. 36, 507 (2006).

${ }^{25} \mathrm{~V}$. Choudhary, V. Rane, and S. Chaudhari, Fuel 79, 1487 (2000).

${ }^{26}$ H. H. Kung, Transition Metal Oxides: Surface Chemistry and Catalysis (Elsevier, Amsterdam, 1989).

${ }^{27}$ K. Dyrek and Z. Sojka, J. Chem. Soc. Faraday Trans. 1 78, 3177 (1982).

${ }^{28} \mathrm{M}$. Niedermaier, C. Taniteerawong, T. Schwab, G. Zickler, J. Bernardi, and O. Diwald, ChemNanoMat 5, 634 (2019).

${ }^{29}$ A. R. Gheisi, M. Niedermaier, G. Tippelt, W. Lottermoser, J. Bernardi, and O. Diwald, Part. Part. Syst. Char. 34, 1700109 (2017).

${ }^{30}$ P. Geysermans, F. Finocchi, J. Goniakowski, R. Hacquart, and J. Jupille, Phys. Chem. Chem. Phys. 11, 2228 (2009).

${ }^{31}$ Y. Su, H. Wei, Z. Zhou, Z. Yang, L. Wei, and Y. Zhang, Mater. Lett. 65, 100 (2011).

${ }^{32}$ S. Coluccia, M. Baricco, L. Marchese, G. Martra, and A. Zecchina, Spectrochim. Acta, Part A 49, 1289 (1993).

${ }^{33}$ S. Hayun, T. Tran, S. V. Ushakov, A. M. Thron, K. van Benthem, A. Navrotsky, and R. H. R. Castro, J. Phys. Chem. C 115, 23929 (2011).

${ }^{34}$ D. Su, N. Jiang, J. C. H. Spence, F. He, and W. T. Petuskey, J. Appl. Phys. 104, 63514 (2008).

${ }^{35}$ N. Jiang, Rep. Prog. Phys. 79, 16501 (2016).

${ }^{36}$ J. Hargreaves, G. Hutchings, R. W. Joyner, and C. J. Kiely, J. Catal. 135, 576 (1992).

${ }^{37}$ S. Stankic, A. Sternig, F. Finocchi, J. Bernardi, and O. Diwald, Nanotechnology 21, 355603 (2010).

${ }^{38}$ K. Kwapien, J. Paier, J. Sauer, M. Geske, U. Zavyalova, R. Horn, P. Schwach, A. Trunschke, and R. Schlögl, Angew. Chem., Int. Ed. 53, 8774 (2014). 